PolymerSupported Synthesis

\section{Key Words}

diarylammonium arenesulfonates esterification

K. ISHIHARA, * S. NAKAGAWA, A. SAKAKURA (NAGOYA UNIVERSITY, JAPAN)

Bulky Diarylammonium Arenesulfonates as Selective Esterification Catalysts

J. Am. Chem. Soc. 2005, 127, 4168-4169.

\title{
Bulky Diarylammonium Arenesulfonates as Selective Esterification Catalysts
}

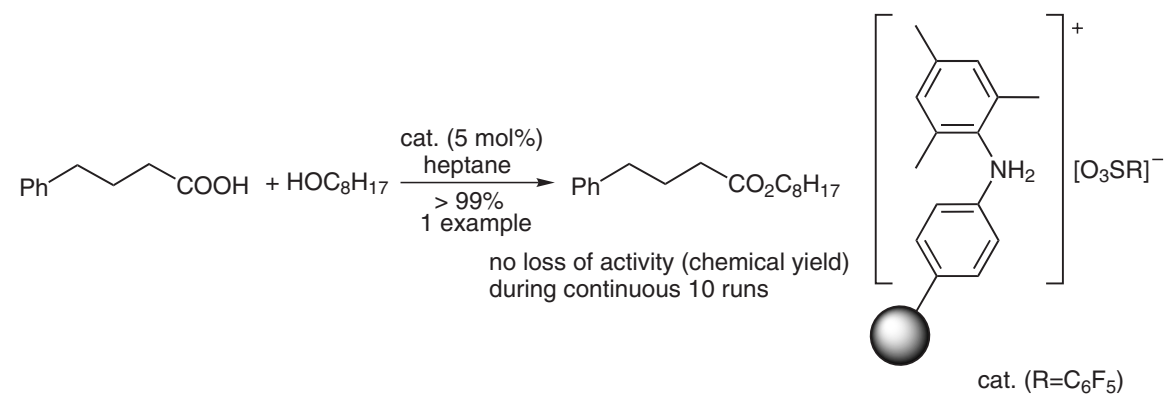

Significance: Polymer-supported bulky diarylammonium arenesulfonate catalyst was found to promote the direct ester condensation reaction of 4-phenylbutyric acid with 1-octanol to give 1-octyl 4 -phenylbutyrate in over $99 \%$ yield. The catalyst was readily recovered and reused by filtration. The recycling of the catalyst was repeated nine times during which no loss of catalytic activity was observed.
Comment: Diarylammonium arenesulfonates were developed as a novel entry of the catalyst promoting direct esterification of carboxylic acids with alcohols. The main part of this paper describes the solution-phase esterification with the new catalyst. Heterogeneous switching of the catalysis makes this paper substantially stronger. 